\title{
Research on Product Design Guided by Museum Heritage
}

\author{
Minfang Li and Minyan Li \\ Jiangxi Science and Technology Normal University, Jiangxi, Nanchang, 330000 China
}

Keywords: Cultural relics; Literary product creation; Design; Museum;

\begin{abstract}
This article looks for some cultural elements from the collection of exquisite cultural relics to inherit and carry forward the spirit and culture expressed in the historical society. The cultural creative products designed in this paper are divided into stone carving series, tile series, bronze series and others. Each cultural and creative product has a text introduction, according to the existing modeling characteristics of cultural relics, the paper try to use the scene in the life practice. These measures are not only a form of development, but also inherit the history behind the collection of cultural relics.
\end{abstract}

\section{Introduction}

Cultural and creative industry is a new industry with creativity in the context of economic globalization. It emphasizes that a subject culture or cultural factor relies on the individual (team) to develop and marketing intellectual property through technology, creativity and industrialization. Cultural and creative industries mainly include radio, film and television, animation, visual arts, crafts, design, environmental art, media, costume design and so on.

In March 7, 2016, UNESCO and the association of international writers and composers jointly launched the latest research report on cultural and creative industries: the global overview of cultural and creative industries. The report shows that the cultural and creative industries are the pillar industries of the global economy and have made great contributions to the world economy and the social employment. Both in the developed and emerging market economies are becoming the strategic assets of the national and regional economies.According to the research report, in 2013, the total income of the global cultural and creative industries totaled 22500 billion US dollars, accounting for 3\% in the total GDP in the world. It has created 27900 thousand jobs for all countries in the world, which account for $1 \%$ in the world's total employment population, higher than the total of the European, Japanese and American auto makers (25 million).On the morning of March 13, 2016, Luo Shugang, Minister of culture, introduced the general idea of cultural construction in the "13th Five-Year" period to the media at the ministerial passage of the Great Hall of the people. He pointed out that "to transform our traditional culture creatively and creatively, to protect our cultural heritage, we should not only protect the material cultural heritage, but also protect the intangible cultural heritage, so that the cultural heritage should be" alive. The so-called "living up" is to let the cultural value of cultural heritage enter the hearts of the people.

China has a long history. Ancient emperors left us countless cultural resources. As of 2012, the total number of museums in China has reached 3589. The cultural relics congealed a lot of etiquette and custom, reflecting the production technology, technical level and living conditions at that time. It also reflected people's understanding and understanding of nature, society and senior people at that time, and also reflected the artistic accomplishment and life interest of the people at that time. Our country's idea of the museum as a national cultural strategy has greatly encouraged us, and this has further strengthened our research direction.

\section{Product design and development}

Among the many collections of cultural relics, several cultural relics are selected for the design and development of cultural and creative products. The type of development is divided into stone carving, tile, bronzes and others.

\subsection{The study of stone sculptures}

1) The stone carving inkstone of Northern Wei Dynasty

The stone carving inkstone is shown in Figure 1. In 1970, the site of the Northern Wei kiln in Datong Chengnan bearing factory was unearthed. As an ancient daily necessities with scholarly flavour, its surrounding 
carved figures, animal riding, dance, and other contents also have a special meaning. The pattern used in this article is used in the decorative walls of life. As shown in Figure two, it meets the theme of ancient stationery and modern books, giving people a mysterious and beautiful visual feeling and unique memory use value.

2) The stone carvings Chi dragon of the Northern Wei Dynasty

Chi dragon is a kind of animal in the legend of Han nationality in ancient times, and belongs to the legendary dragon. The dragon is the most worshipped animal of the Yellow Emperor, and it is decorated on the head of the tablet to become a head. The value of the tablet becomes more noble. The stone carving head was excavated in 1976.

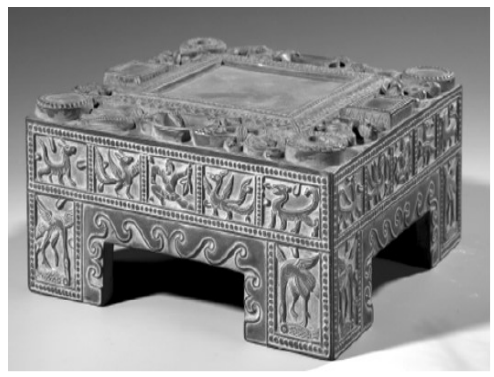

Figure 1. Stone sculptures in the Northern Wei Dynasty

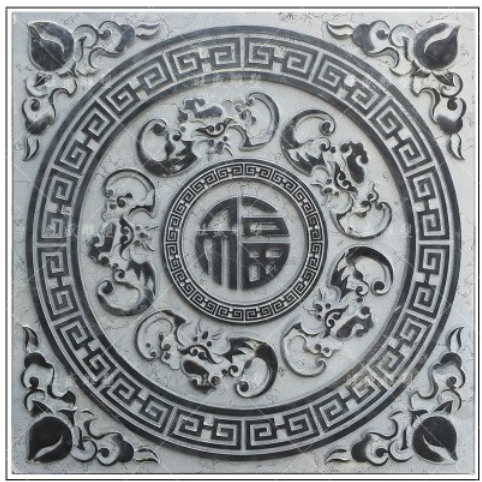

Figure 2. Wall frescoes

The most powerful stone carving Chi head can be designed as a scenic nozzle, as shown in Figure three. This can integrate Chinese culture into architecture, that is beautiful and practical.

3) The eight diagrams of stone carvings in the Jin Dynasty

Stone carving eight diagrams incense burner, excavated from the tomb of Yan De Yuan, Datong gear factory in 1973. The stone carving eight diagrams incense burner unearthed in the tomb is an open, short neck, drum belly, leading ears and three animal feet. The middle part of the abdomen has a geometric pattern, and the upper and lower sides are animal grain and moire. The shape is beautiful and the carving is exquisite. This cup adopts the animal grain pattern on the stone carving eight diagrams incense burner, as shown in Figure four.

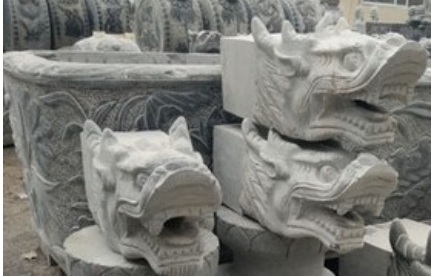

Figure 3. Dragon head

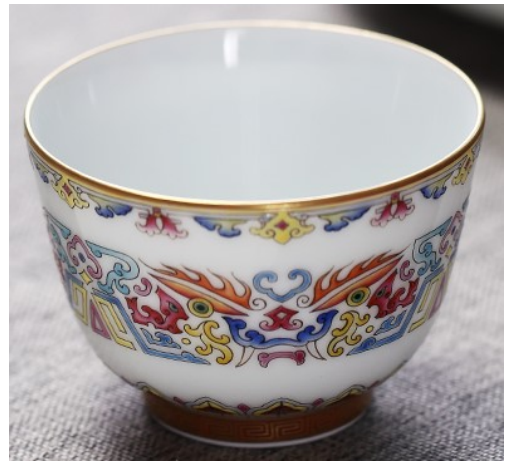

Figure 4. Animal face cup

4) Stone carving dragon pattern pedestal

Stone Carving Dragon Pattern pedestal was excavated at the site of Yunfeng mansion on Dongmen outside Datong in 1998. Stone Carving Dragon Pattern pedestal is modeled on a drum shaped basin with square base and a relief pattern. With a column hole as the center, the surrounding area is decorated with a week of Bead lines, and the outer area is carved with two petals of lotus flower lines, looking down like a blooming lotus; there are two dragon around the abdominal wall, and the body is decorated with scales; The product is designed to be a series of beads and double lotus lines as a pattern or shape carved on T-shirts, make-up mirrors or umbrellas, as shown in Figure 5.

\subsection{Eaves tile}

The animal face eaves tile was excavated at the site of the North Wei 1 building in Datong playground in 2003. With the improvement of art appreciation level in ancient times, eaves tile adorned animals and plants. Eaves tile is the shelter in the front end of ancient building in China. In the Northern Wei Dynasty, the mud eaves tiles were used as building components. We use modern popular color elements to refine animal surfaces and apply them to art paper, as shown in Figure 6. Users have a sense of passing through history.

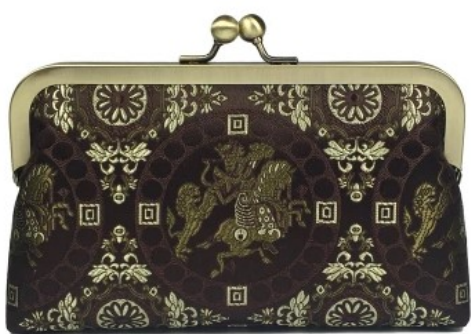

Figure 5. Double petal lotus pattern Handbag 


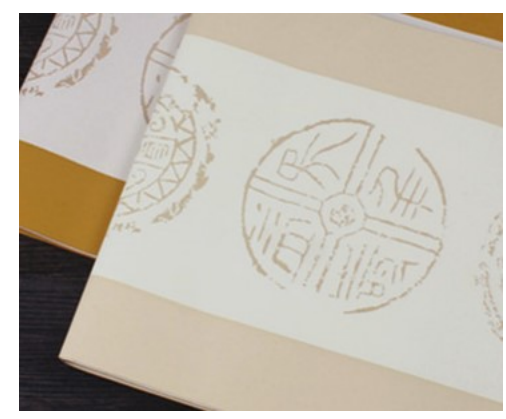

Figure 6. Eaves tiles paper with Northern Wei Dynasty Beasts

\subsection{Bronze head ring of honeysuckle animal face}

Bronze head ring of honeysuckle animal face was excavated at the jijizhuang commune in Datong County in 1981. Animal head applique is a traditional Han Dynasty door decoration with the meaning of exorcism.The ring ornaments on the door are mostly animal rings. It is a kind of animal face pattern. It has a variety of shapes and a ring under the mouth. It is used for decoration on doors.Usually it is made of metal, such as tiger, turtle, turtle, snake and so on. During the Northern Wei Dynasty, animal head applique was mostly decorated on buildings and burial objects. This utensil is paved with a square and high relief.

Beautiful and special animal head applique modeling, combined with the characteristics of the belt in life, the design effect is shown in Figure 7.

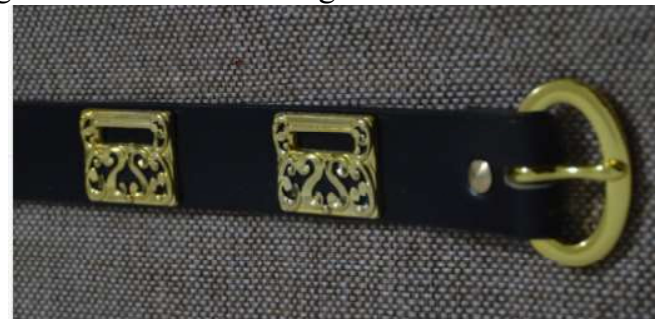

Figure 7. Creative design of belt

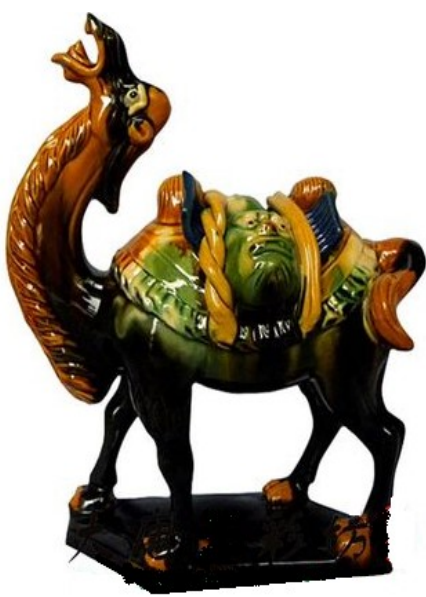

Figure 8. Glazed Camel

\subsection{Other: Glazed Camel}

Glazed pottery camels, excavated from the tomb of Sima Jinlong in ShiJiaZhai village, Datong Chengdong village in 1965. The camels are glazed with brown glaze and head up to the front of the neck. Double peak stands tall and stands upright, just like ready to go. This assembly is a symbol of the civilization of the Silk Road. As the symbol of the Silk Road civilization, the figures and camels in this group have their own unique curve lines. The designers refine them, use the color silk color in the Silk Road as the color of the curve lines, and use it in the printing of the T-shirts in the clothes. You can have close range patterns to highlight the curve dynamics of camels and terracotta figurines, as shown in Figure 8.

\section{Conclusion}

In the process of designing product, we can find out the historical and artistic value hidden behind the cultural relics by selecting the archetype of fine cultural relics and excavating the connotation of cultural relics, and meet the practical needs of life and colorful reality, and enrich the sense of user life, which can let the spirit of ancient artifacts merge into people's daily life and become "living relics".

\section{Acknowledgement}

This research was financially supported by the Project of Teaching Reform of Jiangxi Province in 2017 (Grant NO. JXJG-17-10-10) and the Project of cultural and Artistic Science Planning for Jiangxi Science and Technology Normal University in 2017 (Grant NO. YG2017185).

\section{References}

1. Datong Museum, "the land of the earth -Come into the Datong Museum", Jiangsu Phoenix Art Press, August 2016 edition. (In Chinese)

2. Li Xiaosha and Wang Peilei: Research and development of "Mawangdui health preserving cultural and creative products", "Research on Chinese museum culture industry", Hubei people's publishing house, 2015.(In Chinese)

3. The development of Museum arts and crafts needs to "fly into the homes of ordinary people". [EB/OL] [2018-01-22]http: //news.ifeng.com/a/20150311/43314095_0.sht $\mathrm{ml}$; (In Chinese)

4. Rao Qianqian, Xu Kai Qiang, Li Min. Product design and development research under experience perspective [J]. Design, 2016, (09):30-31.

5. Only by making good use of traditional cultural resources can we create a creative product that moves people. [EB/OL][2018-01-22] http://news.ifeng.com /a/20160312/ 